\title{
Der Erste Weltkrieg in der Lyrik und Essayistik Jozef Wittlins
}

In einem 35 Jahre nach der Veröffentlichung seines einzigen Romans „Das Salz der Erde" verfassten Kommentar zu diesem Werk, dem Essay ${ }_{n}$ Postscriptum zum ,Salz der Erde ““, behauptete der Autor rückblickend, er habe als Soldat der österreichisch-ungarischen Infanterie in den Jahren 1916-1918 „keinen Haß gegen die Feinde, die er in den Russen, Italienern, Serben und Rumänen sehen sollte", empfunden. Im Gegenteil, er habe gegenüber den russischen Kriegsgefangenen, die ihn während verschiedener Aufenthalte in Lazaretten pflegten, Dankbarkeit verspürt sowie Sympathie für die italienischen Kriegsgefangenen, in deren Lager er zeitweise als Dolmetscher fungierte. Wittlin zeigt sich überzeugt davon, dass die Mehrheit seiner Kameraden diese Gefühle geteilt habe. ${ }^{1}$ Trotz der schrecklichen Technisierung und Mechanisierung des Krieges, mit der er wohl weniger zu tun gehabt hatte, war der Erste Weltkrieg seiner Ansicht nach, nicht zuletzt rückblickend im Vergleich mit dem Zweiten Weltkrieg und insbesondere angesichts der Schoah, ein Krieg, in dem die kämpfenden Soldaten nicht aufgehört hatten, einander als Menschen zu betrachten. So heißt es ferner bei ihm: „Trotz aller Greuel des Krieges: Der ,Feind' hörte zumindest meiner Kenntnis nach - außerhalb der Kampfgebiete, wenn er entwaffnet und in Gefangenschaft geraten war, auf, Feind zu sein, und war nur noch unser Kamerad, der sich gleich uns danach sehnte, daß dieser Krieg 20 rasch wie möglich enden möge “. ${ }^{2}$ Diese einfachen Worte drücken das Gleiche aus, was die Expressionisten, auch Wittlin selbst, rund fünfzig Jahre frlther mit der pathetischen O-Mensch-Geste gemeint hatten, die Uberzeugung von der Brüderlichkeit aller Menschen. Bei Wittlin ist diese Uberzeugung mit der judäochristlichen Ethik unterbaut, dass jeder Mitmensch unser Nüchster sel und dass wir diesen Nächsten wenn schon nicht lieben, dann doch respektleren, achten und für seine schmerzvolle Kreatürlichkeit Empathie aufbringen sollen. Die in den angeführten Zitaten durchweg spürbare Relativierung eines national geprägten "Feind“-Begriffs war von Anfang an charakteristisch für seine Einstellung zu den Gegnern Österreich-Ungarns im Großen Kriege.

1 Vgl. Józef Wittlin, Postscriptum zum „Salz der Erde ${ }^{\star}$ nach 35 Jahren, übers. v. Friedrich Griese, in: Ders., Die Geschichte vom geduldigen Infanteristen. Das Salz der Erde. Roman, Ein gesunder Tod. Fragment, Essays, Gedichte, Frankfurt a. M. 1986, S. 388.

2 Ebd. 
Dennoch fühlte sich Wittlin, der 1896 als Jude auf dem ostgalizischen Landgut Dmytrów unweit der russischen Grenze geboren wurde, ein polnisches Gymnasium in Lemberg besuchte und 1914 der polnischen Ostlegion beitrat (die allerdings schon nach einem Monat aufgelöst wurde ${ }^{3}$ ), als Pole, der somit im Ersten Weltkrieg eine schließlich auch genutzte Chance auf die Wiedererlangung der Eigenstaatlichkeit sah. Auch wenn er sich als Pazifist fühlte, unterschied er zwischen der aufgezwungenen Teilnahme am "österreichischen", fremden Krieg und dem Krieg in der Art einer Insurrektion für die Rechte der polnischen (oder einer anderen unterdrückten) Nation. Diese Diskrepanz machte ihm besonders wegen des polnisch-ukrainischen Krieges um Lemberg und Ostgalizien zu schaffen, der am 1 . November 1918 begann. Wittlin sieht im ostgalizischen Bürgerkrieg eine Folge der früheren historischen Konflikte.

Zu erklären ist auch, warum ich mich auf Wittlins Lyrik und Essayistik anstatt auf seinen berühmten, ins Deutsche und in zwölf andere Sprachen übersetzten Antikriegsroman ${ }^{4}$ beziehe, und damit auf Texte, die Nichtspezialisten kaum bekannt sind. Erstens gibt es in dieser Hinsicht vieles nachzuholen, denn nicht nur Polonisten sollten diese ästhetisch vollgültigen Texte kennenlernen, von denen leider nur zwei Gedichte und zwei Essays ins Deutsche übersetzt worden sind. ${ }^{5}$ Zweitens gibt es zum "Salz der Erde" eine nicht unbeträchtliche Menge an Sekundärliteratur, selbst einige Arbeiten in deutscher Sprache. Auch ich habe hierzu beigetragen und 2019 einen Aufsatz zu diesem Roman und seiner Darstellung des Ersten Weltkriegs verfasst, der unlängst von der Szegeder Germanistik herausgegeben wurde. ${ }^{6}$ Daher mein Entschluss, hier den Blick auf einen weniger erforschten, aber bemerkenswerten Teil des Werks von Józef Wittlin zu richten.

$\mathrm{Da}$ ich nicht sicher bin, ob alle Kolleginnen und Kollegen, selbst von polnischer Seite, Wittlin und sein Schaffen kennen, möchte ich anfangs kurz seine Biografie und sein quantitativ zwar eher spärliches, aber qualitativ durchaus beachtliches Werk vorstellen. Obwohl Wittlin, wie gesagt, in der ostgalizischen

3 Vgl. Józef Buszko, Wielka Historia Polski, Bd.8: Od niewoli do niepodległości (18641918), Kraków 2000, S. 344-345.

4 Vgl. Ewa Wiegandt, Wstęp, in: Józef Wittlin, Sól ziemi, opracowanie Ewa Wiegandt, Wroclaw 1991, S. LXXX. "Das Salz der Erde" wurde bald nach seinem Erscheinen ins Deutsche (mit einer Vorrede Joseph Roths), Dänische, Russische, Englische, Französische, Schwedische, Ungarische, während des Zweiten Weltkriegs ins Hebräische und Kroatische und 1945 ins Spanische übersetzt.

5 Die Gedichte „Hymne über einen Löffel Suppe ${ }^{\alpha}$ und die spätere „Litanei“ wurden von Karl Dedecius, die Essays "Krieg, Frieden und die Dichterseele ${ }^{\alpha}$ sowie ${ }_{n}$ Postume Schriften und "Das Postscriptum zum ,Salz der Erde" nach 35 Jahren“ von Friedrich Griese ins Deutsche übersetzt.

$6 \mathrm{Vgl}$. Maria Kłańska, Das Individuum und die Masse im Antikriegsroman von Józef Wittlin „Das Salz der Erde. Die Geschichte vom geduldigen Infanteristen (1935), in: Detlef Haberland u.a. (Hg.), Literarische Bilder vom Ersten Weltkrieg. Exemplarische Analysen, Wien 2019, S. 143-158. 
Provinz aufwuchs, fühlte er sich als Lemberger, da er in der Metropole Galiziens 14 Jahre lang vor allem während der prägenden Gymnasialzeit gelebt hatte. Seine Erinnerungen an diese Stadt, ,Mein Lemberg ( er $1946 \mathrm{im}$ amerikanischen Exil verfasste, geben ein suggestives, anschauliches Bild dieser Stadt vor 1939. Nach der Auflösung der polnischen Ostlegion ging er 1914 zusammen mit Fluten anderer ostgalizischer Flüchtlinge aus den Kriegsgebieten nach Wien, wo er einen Onkel hatte, besuchte dort zuerst ein polnisches Gymnasium, machte das Abitur und begann an der Philosophischen Fakultät der Universität zu studieren. Dort lernte er seinen Landsmann Joseph Roth kennen, der ein enger Freund werden sollte und dessen Werke er ausgezeichnet ins Polnische übersetzte. ${ }^{7}$ Obwohl die beiden vom Kriegsdienst wegen zu schwacher körperlicher Verfassung suspendiert waren und sich als Pazifisten, Schüler von Karl Kraus, bekannten, traten sie 1916 freiwillig in die Armee ein. Während der Ausbildungszeit in Wien aber lernten sie die Rekrutenschinderei kennen und hatten schon genug vom Militär, bevor sie mit dem Krieg konfrontiert wurden. Dann wurde Wittlin einem Marschbataillon in Galizien zugeteilt. Wie Ewa Wiegandt, die Herausgeberin der Ausgabe von „Das Salz der Erde“ im renommierten Ossolineum-Verlag, die auch die Einleitung verfasst hat, nach der Memoirenautorin Zofia Starowieyska-Morstinowa angibt, erkrankte Wittlin bald am damals lebensgefährlichen Scharlach und so beschränkte sich seine Kriegsteilnahme auf Aufenthalte in verschiedenen Lazaretten und Rekonvaleszentenheimen, sowie später auf den Hilfsdienst, u. a. als Dolmetscher in einem italienischen Gefangenenlager. ${ }^{8}$

Nach Kriegsende kehrte er nach Lemberg zurück und erlebte den Bürgerkrieg zwischen Polen und Ukrainern. In seinem Essay n Aus den Erinnerungen eines ehemaligen Pazifisten“ (1929) beschrieb er seinen Gewissenskonflikt:

Wie idyllisch in seiner Einfachheit erschien damals dieser ganze monatrous Weltkrieg, während dessen ich ein reines Gewissen hatte, da ich thm gegen. über eine Widerstandshaltung einnehmen konnte. Dagegen stellte der polniuch. ukrainische Krieg, mit seinem Lemberger Judenpogrom, mich auf Schrlil und Tritt vor tragische Dilemmata, die weder mein Gewissen noch meine Vernunfl beantworten konnten. Während ich den österreichiechen Krieg mit ruhlyein Gewissen als Verbrechen bezeichnen durfte, für das Monarchen, Diplomalen. Journalisten und Lieferanten Verantwortung trugen, wie sollte ich mich dennn gegenüber den Kämpfen um Lemberg verhalten, deren Resultat mir kelnenwoyn

7 Wittlin übersetzte folgende Romane Roths: "Hiob" (1931), "Die Fluch ohne IIn de" (1931), "Zipper und sein Vater" (1931), "Beichte eines Mördere" (1937) und dle

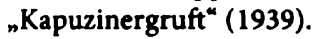

8 Vgl. Wiegandt, S. XI; Zofia Starowieyska-Morstinowa, Ci, których spotykałam, Krakow 1962, S. 83. 
gleichgültig war? Durfte ich dann - angesichts des von mir ersehnten polnischen Sieges - die Augen vor dem dreitägigen Judenpogrom verschließen? ${ }^{9}$

Aus diesem verzweifelten Dilemma habe ihn ausschließlich die Dichtung gerettet. Nach seiner eigenen Aussage entsprangen seine ${ }_{n} \mathrm{Hymnen}^{\prime}$, sein erstes wichtiges Werk, ebendiesen Erlebnissen. ${ }^{10}$

Im freien Polen versuchte Wittlin zuerst als Lehrer in Lemberg und dann als literarischer Leiter am Stadttheater in Lodz sein karges Brot zu verdienen. In der Zwischenkriegszeit reiste er als Stipendiat des polnischen Staates ab 1925 viel nach Italien, Frankreich und Jugoslawien und gab seine Eindrücke dann in den Reisebildern "Etappen “ ("Etapy ${ }^{\alpha}, 1933$ ) wieder. Seit er 1925 die Arbeit an seinem großen Roman über den Ersten Weltkrieg aufgenommen hatte, begab er sich immer wieder auf Recherchen ins Kriegsmuseum in Vincennes bei Paris und genoss die Arbeit in der Abgeschiedenheit der ehemaligen Abtei de Royaumont. ${ }^{11}$ Die Auslandsreisen halfen ihm die Hetze gegen ihn als Kriegsgegner und Juden im Polen der dreißiger Jahre zu ertragen. ${ }^{12}$ Er weilte gerade im Ausland, als der Zweite Weltkrieg ausbrach, was ihm als geborenem Juden wahrscheinlich das Leben rettete. Er blieb in Frankreich, es gelang ihm mit Mühe, Frau und Kind nachkommen zu lassen, es folgte eine Flucht auf der üblichen Flüchtlingsroute durch ganz Europa und schließlich mit dem Schiff in die USA. Da er nach dem Zweiten Weltkrieg den Polen aufgezwungenen "Kommunismus" nicht mit seinem Gewissen vereinbaren konnte, blieb er bis zu seinem Tode im Jahre 1976 in New York, schwer unter der geistigen und materiellen Misere des Exils leidend, ohne wieder ein literarisches Werk schaffen zu können.

Wittlin wird meist entweder als Verfasser nur eines Werkes wahrgenommen, und zwar des Romans über den Ersten Weltkrieg, der eigentlich eine Trilogie sein sollte, die aber entweder auf der Flucht verlorenging oder in weiteren Teilen nicht zustande kam, ${ }^{13}$ oder dreier Werke, neben dem ${ }_{n} \mathrm{Salz}$ der Erde “ der expressionistischen ${ }_{n}$ Hymnen " und der Übersetzung der homerschen ${ }_{n}$ Odyssee“. Die Wittlin-Kennerin Ewa Wiegandt behauptet: „Er [Wittlin] schrieb wenig, da ihn im Grunde sein Leben lang drei Werke interessierten: die polnische Fassung der ,Odyssee, die ,Hymnen' und ,Das Salz der Erde ${ }^{\text {ic }} .{ }^{14}$

9 Józef Wittlin, Ze wspomnień byłego pacyfisty, in: Ders., Orfeusz w piekle XX wieku, Kraków 2000, S.78. Wenn nicht anders angegeben, stammen alle Ubersetzungen von der Autorin des Aufsatzes.

10 Vgl. ebd., S. 79.

11 Vgl. Józef Wittlin, Z walizy francuskiej, in: ebd., S.228-234; Ders., Abbaye de Royaumont, in: ebd., S.291-302.

$12 \mathrm{Vgl}$. Wiegandt, S. XXXV.

13 Vgl. ebd., S. XLVII-XLVIII sowie Marian Stępień, Inwalida pierwszej wojny światowej, in: Ders., Wśśód emigrantów, Kraków 2007, S. 165-177, hier S. 173-174.

14 Wiegandt, S. XII. 
Auf "Das Salz der Erde" werde ich in diesem Beitrag kaum eingehen, es sel lediglich erwähnt, dass es ein Kriegsroman ist, der nicht den Krieg selbst, sondern die Kriegserklärung, die Reaktionen darauf und die Einberufung und militärische Grundausbildung der Rekruten, zumeist einfacher ostgalizischer Bauern, darstellt. In Polen gilt der Roman als eine Art Epos in Prosa. Uber das Handlungsmuster, die Form des Romans und seinen Protagonisten, einen Analphabeten aus der Huzulei, den Ostkarpaten, schrieb der Altphilologe Zygmunt Kubiak im Nachwort zur Ausgabe von 1979 u.d.T. „Der polnische Nachkomme Homers“: „,Das Salz der Erde“ ist eine Art ,Odyssee;, in der allerdings nicht der König Odysseus, sondern der Schweinehirt Eumaios der Held ist". ${ }^{\text {. }}$

Zunächst möchte ich kurz die "Odyssee" -Ubersetzung ansprechen, da ihr Entstehen mit dem Ersten Weltkrieg und dem Bürgerkrieg von 1918/19 zusammenhängt. Wittlin war ein begabter, perfektionistischer Übersetzer, der drei poetische Fassungen des Epos veröffentlichte: 1924, 1931 und 1957. Der ersten Fassung stellt er ein Gedicht "Elegie an Homer" ("Elegia do Home$\mathrm{ra}^{\text {") }}$ voran, wo die Sprecherinstanz in Ich-Form als Übersetzer der "Odyssee" erklärt, sie habe während des Großen Krieges entdeckt, dass Homer keine Lektüre zum Quälen der Schüler sei, sondern dass man sich mit seinen Helden identifizieren könne:
Und einmal im Lazarett,
in einem schrecklichen Krieg
Sprachst du zu mir ruhig
davon, dass Städte brennen.
In mein viehisches Leben
drangst du ein mit dem König der Ithaker
Er reichte die Hände meiner Qual. ${ }^{16}$

Der Expressionismus ist in der polnischen Dichtung eine Randerscheinung, vor allem auf die Posener Gruppe Zdrój (Die Quelle) beschränkt. Das hervorragendste lyrische Werk dieser Richtung ist zweifellos Wittlins HymnenSammlung (1920). In diesem Jugendwerk ist die pazifistische Haltung des Autors besonders spürbar, was ebenfalls eine untypische Erscheinung in der polnischen Poesie war, denn nach der Wiedererstehung Polens nach 123 Jahren überwog in Bezug auf den Krieg die tyrtäische Siegesstimmung oder aber die Überzeugung, die Poesie müsse nun endlich nicht mehr ihre langjährige Bestimmung, das Gewissen der Nation zu sein, erfüllen. Die Stimme des jun-

15 Zygmunt Kubiak, Polski homeryda, in: Józef Wittlin, Sól ziemi. Powiesć o cierpliwym piechurze, Warszawa 1988, S.263. Ich erlaube mir, die Ubersetzung des Zitats von Andreas Lawaty zu übernehmen. Vgl. Andreas Lawaty, Der Autor, in: Wittlin, Die Geschichte vom geduldigen Infanteristen, S. 393-401, hier S. 396.

16 Józef Wittlin, Elegia do Homera, in: Ders., Wybór poezji, wstęp i nota biograficzna Wojciech Ligęza, Kraków 1991, S.99. 
gen Wittlin stellt eine Ausnahme dar, da sie stärker als die Daseinsfreude, obwohl auch diese in den Hymnen vorkommt, das erfahrene Leid des Krieges ausdrückt, in dem der Nächste willkürlich zum "Feind“, zum Anderen, Fremden abgestempelt wurde und die Brüder einander töten mussten.

Nicht alle der ursprünglich 21 Hymnen ${ }^{17}$ beziehen sich auf den Krieg. Ihr allgemeines Thema ist der Diskurs über den Sinn des menschlichen Lebens und Todes, das Hadern mit Gott und die Hoffnung auf eine moralische Erneuerung. Doch der Krieg, sowohl der Erste Weltkrieg und der polnisch-ukrainische Bürgerkrieg als auch der Krieg allgemein, ist eine wichtige thematische Komponente und Voraussetzung der Gedichte. Wiegandt macht auf die Nähe Wittlins zum deutschen Expressionismus in seiner aktivistischen und, wie sie es nach Krystyna Jakowska nennt, kommunionistischen Variante aufmerksam. Mit „Kommunionismus" ist eine Variante des Expressionismus gemeint, die besonderen Nachdruck auf tätige Nächstenliebe und die Úberzeugung von der Brüderlichkeit aller Menschen legt. ${ }^{18}$

Den Hymnen wird als eine Art Proömium das Gedicht "Aufgesang“ ( ${ }$ Przedśpiew") vorangestellt. Der lyrische Sprecher erinnert darin in einer Geste der Menschheitsverbrüderung an die jüngste Vergangenheit, denn er habe noch den "Schrei der sterbenden Bataillone" in den Ohren,

in der Lunge Giftgas und Asche, und die Feuersbrunst

Der Welt, die im Hals jedes Wort erstickt. ${ }^{19}$

In der fünften Strophe wird die Hoffnung auf das Morgen ausgedrückt, denn er erwarte, dass die Klagen von ganz Europa nicht umsonst sein werden. Schlüssigerweise heißt die zweite der Hymnen "Die Todesfurcht" ("Trwoga przed smiercia $\left.{ }^{\prime \prime}\right)$ und ihre Sprecherinstanz wendet sich in der Rolle des Soldaten direkt an Gott mit einem flehenden Ruf, der als Refrain erscheint: „Herr! Ich will nicht sterben! ${ }^{\star 20}$ Diese Bitte um Erbarmen erfolgt individuell und im Namen der ganzen Menschheit.

Wittlin selbst zählte zu den Texten, die unmittelbar aus der Erfahrung des polnisch-ukrainischen Krieges entstanden, solche Hymnen, wie die zwei wohl bekanntesten, ${ }_{n}$ Die Hymne über einen Löffel Suppe ${ }^{\text {( }}{ }_{n}$ Hymn o łyżce zupy $^{\mu 21}$ ) und "Das Begraben eines Feindes ${ }^{\prime \prime}$ ("Grzebanie wroga ${ }^{\alpha}$ ). Ferner gehören

17 In der zweiten Auflage hat Wittlin sechs Texte nicht mehr abdrucken lassen, wahrscheinlich weil sie zu modernistisch („jungpolnisch“) klangen. In „Wybór poezji“ befinden sie sich unter ${ }_{n} \mathrm{Z}$ pierwszego wydania hymnów“, S. 162-197. Es handelt sich um die

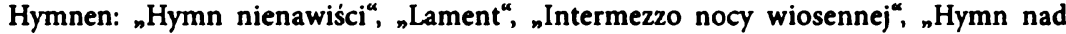
hymnami“, nZapowiedź dnia jutrzejszego “, „Kantata dziecinna“.

$18 \mathrm{Vgl}$. Wiegandt, S. XVI und XXI. Krystyna Jakowska benutzt diesen Begriff in ihrer Monografie. Krystyna Jakowska, Z dziejów ekspresjonizmu w Polsce. Wokól "Soli ziemi“, Wrocław 1977, S. 10, 16-17.

19 Józef Wittlin, Hymny, in: Ders., Wybór poezji, S. 29.

20 Ebd., S. 30-36.

21 Vgl. Wittlin, Die Geschichte vom geduldigen Infanteristen, S.7-8. 
dazu "Hymne des Hasses" („Hymn nienawisci“), "Wiegenlied“ ("Kotysanka"), "Sehnsucht nach dem Freund" ("Tesknota za przyjacielem"), "Todesfurcht" ("Trwoga przed śmiercia"). Die Problematik des Krieges wird ebenfalls in dem allegorischen, ironischen "Lob des Schwertes" ("Pochwala miecza") oder in der Hymne "An den Gegner" ("Do przeciwnika“) berührt. Gerade diese Hymnen haben, wie Wittlin in seinen "Erinnerungen eines ehemaligen Pazifisten" schrieb, einen Gehalt voller ${ }_{n}$ wörtlicher Authentizität ${ }^{\alpha 2}{ }^{22}$ Damit meinte er die vielen naturalistischen, turpistischen konkreten Bilder und Situationen in den Gedichten, das direkte Benennen der entstellten Leichname oder gar abgerissener Körperteile und die Einfügung solcher Details, wie die roten Läuse, die die Soldaten bissen, das Trinken von vergiftetem Wasser, die tagelangen zermürbenden Märsche, das Kriechen in den Gräben, um nicht erschossen zu werden. Wiegandt weist darauf hin, dass solche Bilder zur pazifistischen Topik gehören. ${ }^{23}$ Gleichzeitig stellt sie fest, dass die ${ }_{n}$ Hymnen ${ }^{4}$ die philosophisch-ästhetischen Voraussetzungen des Expressionismus erfüllen: sie sind eine disharmonische, aus Widersprüchen und Kontrasten gebaute Expression der menschlichen Seele, die nach der Transzendenz, nach der Sphäre des Geietes strebt ${ }^{4}{ }^{24}$ So beschreiben die "Hymnen" meist naturalistisch, manchmal allegorisch die Sphäre des Materiellen, Körperlichen und schweben daruber hinaus in die Sphäre des Geistes, der "Seele“, wie Wittlin sie im Einvernehmen mit der modernistischen und expressionistischen Begrifflichkeit nannte. ${ }^{25}$

Was an den Hymnen am meisten beeindruckt, ist die darin ausgesprochene Überzeugung, dass derjenige, den die Befehlshaber oder auch das eigene Nationalgefühl als nFeind" bzw. als Gegner betrachten lassen, nicht der Andere, ${ }^{26}$ sondern unser Bruder, unser Nächster ist. Sie fußt in der jüdischen, von Christus übernommenen und auf alle Menschen erweiterten Ethik. Diese Verantwortungsgeste führt im Gedicht ${ }_{n}$ Das Begraben eines Feindes ${ }^{*}{ }_{n}$ Grzebante wroga ${ }^{a}$ ) dazu, dass sich der Sprecher ${ }_{n}$ ein vergiftetes Herz" zuschreibt, ausgehend von der konkreten Situation eines Soldaten, dem die Pflicht aufgetragen wurde, einen im Kampf gefallenen Gegner zu begraben. Der Gefallene wurde ihm als "Feind" mit dem Finger gewiesen, der Sprecher beginnt aber zu gru-

22 Wittlin, Ze wspomnień bylego pacyfisty, S. 79 .

23 Vgl. Wiegandt, S. XVIII.

24 Ebd., S. XVI.

25 Vgl. Maria Kłańska, Der galizische Expressionismus, in: Klaus Amann/Armin A. Wallas (Hg.), Expressionismus in Osterreich. Die Literatur und die Künste, Wien 1994, S. 353373, hier S. 360.

26 Vgl. Józef Olejniczak, Wittlin wobec „Innego", in: Anna Frajlich (Hg.), Between Lvow, New York and Ulysses' Ithaca. Józef Wittlin. Poet, Essayist, Novelist, Torun 2001, S. 113125, sowie Joanna Kosturek, die einen Zusammenhang mit der Philosophie von Levinas herstellt, Joanna Kosturek, Bliźni w świecie poetyckim Józefa Wittlina. Wokół zagadnień metafizycznych i moralnych, in: Wojciech Ligęza / Wojciech S. Woclaw (Hg.), Etapy Józefa Wittlina, Kraków 2014, S.90-113, hier S.111-113. 
beln, wer sein Feind gewesen sein könnte. Mütze und Knöpfe, ein pars pro toto, dessen sich Wittlin auch im "Salz der Erde" gerne bedient, weisen den Toten als Soldaten der gegnerischen Armee und damit als „Feind“ aus. Wie es Hubert Orłowski prosaisch übersetzt:

Ich greife nach der Schaufel, obwohl ich nicht weiß, wer mein Feind ist: Bauer oder Herr, oder Arbeiter, ein böser Mensch oder ein edler. - Nur eines weiß ich: ein Feind. [...] Obwohl die Hand, die die Waffe hält, [ebenso schmerzend und M.K.] ebenso müde ist wie die Hand meines Bruders. Wie soll ich dich begraben, du mein verstummter Feind, da du bist wie [mein] Bruder? Wie soll ich dich begraben, du verkrümmte Leiche, da dich mein Bruder getötet hat? ${ }^{27}$

Es folgt die Uberlegung, dass sie beide auf derselben Muttererde, vielleicht gar auf derselben Scholle geboren und von ihr ernährt wurden. Die authentische Situation des polnisch-ukrainischen Krieges wechselt hier zur Perspektive des Ersten Weltkriegs, denn der getötete Feind erscheint als ein zwangsrekrutierter Soldat, der nach dem Willen der militärischen Führer (Monarchen und Politiker) und angeblich auch Gottes am Krieg auf der Gegenseite teilnahm. Die ökonomischen Gründe des Krieges werden hervorgehoben. Im Nachdenken

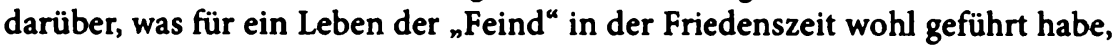
stellt sich das Gefühl ein, es sei ein Leben wie das eigene gewesen. Daher kann das Ich sein "vergiftetes Herz" nicht vergessen. Im zweiten Teil des Gedichts folgt mit einer Vision eines mystischen Jenseits, in dem alle gleich und verbrüdert sein werden, der Versuch, sich zu trösten. Der dritte Teil zeigt jedoch, dass sich das Ich nicht beruhigen kann, vor Groll den Leichnam zu beleidigen beginnt und dann in einer Rahmenschließung des Gedichts noch einmal die Klage um den Gestorbenen anhebt und zugleich um sein eigenes vergiftetes Herz".

Auch die ${ }_{n}$ Hymne über einen Löffel Suppe" ist ein Du-Gedicht, in dem sich die sprechende Instanz an einen toten Kameraden, egal ob Freund oder Feind, wendet. Hier ist diese Identifizierung mit dem $\mathrm{Du}$, mit dem Anderen noch deutlicher. Das Ich möchte, zu spät, wie es weiß, dem toten Soldaten einen Löffel warmer Suppe reichen, nach dem sich der in fremder Erde Erfrorene umsonst gesehnt hatte. In drei Langstrophen wird das existentielle Elend des ehemals marschierenden, wachestehenden und frierenden, nun aber toten Soldaten rekapituliert, der Bruder genannt wird. ${ }^{28}$ Weder der Gestorbene noch die Ich-Figur wissen, warum er alle diese Qualen erlitten, wofür er gekämpft hat. Damit werden auch in diesem Gedicht die dem einfachen Soldaten unver-

27 Vgl. Wittlin, Grzebanie wroga, in: Ders., Wybór poezji, S. 37. Die Ubersetzung des Zitats von Hubert Orłowski, Pazifismus und Kakaniens Untergang im Schaffen von Józef Wittlin, in: Klaus Amann/Hubert Lengauer ( $\mathrm{Hg}$.), Osterreich und der Große Krieg 19141918. Die andere Seite der Geschichte, Wien 1988, S. 260-265, hier S. 262.

28 Vgl. Józef Wittlin, Hymne über einen Löffel Suppe, übers. v. Karl Dedecius, in: Ders., Die Geschichte vom geduldigen Infanteristen, S.7-8. 
ständlichen Kriegsgründe noch einmal evoziert, die mit dessen Bedürfnissen nichts zu tun hatten. Während der Kältetod sich ihm näherte, habe er weder nach Mutter noch Vater, noch nach seiner Frau gerufen, sondern nach einem Löffel warmer Suppe. Die körperlichen Bedürfnisse und Nöte überstiegen die geistigen und seelischen. Das Ich fühlt die Verantwortung für den Toten, daher möchte es ihm Hilfe leisten, von der es weiß, dass sie zu spät kommt.

Nicht alle Hymnen drücken sich mit solcher Deutlichkeit aus, aber alle äußern, manchmal als expressionistischer Schrei, das Leid der Kreatur im Krieg oder in einer anderen existentiellen Grenzsituation. Der Gott des Alten Testaments wird dabei meist als eine bedrohliche, gerechte, aber unbarmherzige Instanz evoziert, die um Erbarmen angefleht wird, oder darum, wie in der „Hymne der Hymnen ( „Hymn nad hymnami“), zu existieren, sich nicht als eine bloße Erfindung des menschlichen Geistes zu erweisen und auch nicht tot zu sein, wie man nach dem Ersten Weltkrieg oft meinte. Christus erscheint dagegen nicht als Gottheit, sondern als Figur des Leids, als der Barmherzige, der aber selbst ein Opfer menschlicher Bosheit ist. Man kann die "Hymnen" als den einzigen vollgültigen Ausdruck polnischer expressionistischer Dichtung betrachten, aber auch - wie bei Joanna Kosturek - als Ausdruck einer Verantwortung, die sich nicht im abstrakten Mitleid erschöpft, sondern nach einer konkreten Hilfeleistung für das $\mathrm{Du}$, auch wenn es ein Kriegsgegner sei, verlangt. ${ }^{29}$

Über diese drei Werke hinaus, die "Hymnen", die "Odyssee"-Ubersetzung und „Das Salz der Erde“, war Wittlin auch ein begabter Essayist und Feuilletonist. Die 1962 im Exil veröffentlichte umfangreiche Auslese seiner nicht-fiktionalen Texte umfasst sowohl frühere Sammlungen als auch verstreute Texte. Auf den Ersten Weltkrieg bzw. das Phänomen des Krieges überhaupt und die Nachkriegssituation rekurrieren besonders ${ }_{n} \mathrm{Krieg}$, Frieden und die Dichterseele $^{\prime \prime}(1923 / 24)^{30}$ und "Aus den Erinnerungen eines ehemaligen Pazlfisten" (1929). ${ }^{31}$ Die beiden Essays sind in mehrere Unterkapitel geteilt und rekonstruieren systematisch die Haltung des Schriftstellers dem Krieg gegenuber. Der Posener Germanist Hubert Orłowski meint in seinem Aufsatz „Pazifismus und Kakaniens Untergang im Schaffen Józef Wittlins", dass Wittlin im Eceay aus den Jahren 1923/24 als erster Antikriegsautor zwei Dinge unternommen habe: Erstens habe er die "Zweckmäßigkeit pazifistischer Haltungen im Lichte

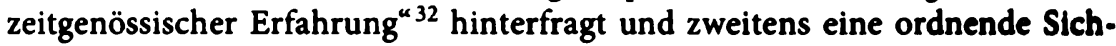
tung pazifistischer Literatur in Europa durchgeführt. Die Kenntnisse Wittlins bezüglich der zeitgenössischen Literatur, die sich mit dem Ersten Weltkrieg

29 Vgl. Kosturek, S. 90-113, hier S. 110.

$30 \mathrm{Vgl}$. Józef Wittlin, Wojna, pokój i dusza poety, in: Ders., Orfeusz w piekle XX wieku, S. 16-44. Die deutsche Ubersetzung von Friedrich Griese in: Ders., Die Geschichte vom geduldigen Infanteristen, S. 327-365.

31 Wittlin, Ze wspomnień bylego pacyfisty, S. 73-91.

32 Vgl. Orłowski, S. 263. 
auseinandersetzt, sind in der Tat imponierend. Dabei befasst er sich nicht nur mit den Autoren, die Pazifisten sind, sondern auch mit Kriegsbefürwortern und versucht selbst unter diesen zu differenzieren. Die einfachste Einteilung trifft er jedoch zwischen Dichtern, die als Soldaten am Ersten Weltkrieg teilnahmen, und solchen, die es nicht oder in privilegierter Stellung taten, z. B. als Presseberichterstatter. Seine Beobachtung ist, dass die überwiegende Mehrheit der Kriegsteilnehmer sich als Gegner des Krieges äußert, während unter denjenigen, die nicht aktiv teilgenommen haben, die Mehrheit den Krieg bejaht.

Bevor der Autor zur Rolle der "Dichterseele ${ }^{\alpha}$ angesichts des Krieges übergeht, beschreibt er die anfängliche allgemeine Kriegsbegeisterung und die aufhetzende Funktion der Presse bei Kriegsbeginn und kontrastiert damit die Ergebnisse des Krieges, die Millionen von Toten, die Kriegsversehrten und Schwerbehinderten sowie diejenigen, die der Krieg um den Verstand gebracht hat, die an verschiedenen Kriegstraumata leiden, schließlich diejenigen, die ihrer Taten wegen ihr Gewissen nicht beruhigen können. Wittlin kritisiert, wie aus der von staatlichen Institutionen kontrollierten, in Friedenszeiten nur von wenigen ausgeübten und meist mit schweren Strafen belegten Fähigkeit zu Töten eine Tugend gemacht wird, sobald ein Krieg ausbricht. Neben dem Staat, der plötzlich eine Umwertung der bisher geltenden Normen durchsetzt, werden die Kirchen und Religionen angeprangert, die Gott für die Sache der Kriegsparteien zu vereinnahmen, zu instrumentalisieren suchen und die Soldaten mit dem Segen und der Überzeugung in den Kampf entlassen, dass Gott auf ihrer Seite sei. Wo also die Religion nicht protestiert, ergreifen die Dichter als eine moralische Instanz das Wort, sie brechen mit dem Ästhetizismus der Moderne, der vor allem nach der Schönheit, der Vollkommenheit der Form fragte, und wollen Stellung beziehen. Wittlin kritisiert aber, dass dies meist in falscher Weise geschehe, entweder indem der Krieg befürwortet und der

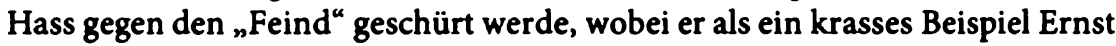
Lissauers ${ }_{n}$ Haßgesang auf England ${ }^{\mu 33}$ anführt, oder aber ein naiver Pazifismus vertreten werde. Diese Haltung sei genauso dilettantisch wie die der Nationalisten, die die ethischen Probleme des Krieges auf eine nationale oder staatliche Notwendigkeit verengen. Dabei ist Wittlin weit davon entfernt, die beiden Haltungen in ethischer Hinsicht gleichzusetzen. Seiner Meinung nach bildet ja die ganze Menschheit eine Einheit, eine Gattung, folglich ist jeder Krieg ein Bruderkrieg und der Mensch das einzige Tier, das sich gegen die eigene Gattung wendet. ${ }^{34}$ Seitdem aber die christliche Ethik als Maßstab von den meisten aufgegeben worden sei, sei dieses Problem unlösbar geworden. Die Angehörigen einer Nation würden darauf trainiert, den Nächsten jenseits der Grenze zu hassen und als „Feind“ zu bezeichnen, nur weil ihr Gebieter sein

33 Wittlin, Krieg, Frieden und die Dichterseele, in: Ders., Die Geschichte vom geduldigen Infanteristen, S. 334.

34 Vgl. ebd., S. 340, 354. 
Territorium erweitern möchte. Wittlin nennt diese Dressur, die dann vor allem auch bei der Ausbildung in der Armee erfolgt, die Mechanisierung des Menuchen. Dieser Prozess wird von Wittlin später im Roman "Das Salz der Erde" thematisiert, wo eindringlich gezeigt wird, wie aus individuell denkenden und fühlenden Menschen Automaten gemacht werden, die aus Angst vor Strafmaßnahmen ihren Vorgesetzten unbedingt gehorchen. Wittlin entblößt die patriotische Propaganda von allem Pathetischen und verweist darauf, dass die Gründe für den Ersten Weltkrieg keineswegs erhabener waren als diejenigen früherer Kriege: „Trotz aller erhabenen Ideale, die von den Machthabern und Führern verkündet wurden, kämpfte Europa in den Jahren 1914 bis 1918 um seine Nahrung, um den Besitz der Früchte der Erde und um Absatzmärkte für seine Waren. Es ging vor allem um materielle, kommerzielle Interessen". ${ }^{35}$ So dekonstruiert er die patriotische Mythologie des Krieges.

Bereits in dieser Skizze differenziert Wittlin zwischen solchen Kriegen, an denen die Untertanen eines Staates gezwungenermaßen teilnehmen, und Be. freiungskriegen. Als Beispiele eines Krieges nvom Typ des Aufstands" 36 nennt er den Verteidigungskrieg der Serben, der Belgier gegen Deutschland, cowle den Kampf der Polnischen Legionen unter Józef Pilsudski um die Wlederherstellung des polnischen Staates. Dabei geht er auf das Unrecht der Tollungen Polens ein und klagt die damaligen Regenten Preußens, Osterrelchs und Russlands an, dass sie ganze Generationen von Polen gezwungen haben, „ihre unschuldigen Nächsten: die Russen, die Deutschen und Osterreicher, zu hassen, und sie sind bis zum heutigen Tage von diesem Haß erfüllt! Möge uns die junge polnische Freiheit von der Todsünde des Brudermordes freisprechen, zu der ihr uns gezwungen habt!".37

Gegen Ende der Skizze wird die sprechende Instanz euphorisch. Sie behauptet, nach solch einer apokalyptischen Katastrophe, nach einem Völkermorden derart monströsen Ausmaßes, werde es keine Kriege mehr geben. Der eben entstandene Völkerbund, das internationale oberste Gericht seien dazu berufen, Streitigkeiten zwischen den Nationen auf friedlichem Wege beizulegen. Schon Immanuel Kant hatte ja den Plan einer Weltregierung ausgearbeitet, die für den Weltfrieden sorgen sollte. Zum Schluss geht der Sprecher von der politischen Vision wieder zu einer poetischen über. Er entwirft das Bild eines Friedensreiches, das alttestamentliche Wurzeln in der Vision des Jesaja hat. ${ }^{38}$ Gleichzeitig drückt er die utopische Hoffnung aus, dass zum Kommen eines solchen messianischen Zustandes die Dichter beitragen werden.

Der Essay aus dem Jahre 1929 trägt den programmatisch-polemischen Titel "Aus den Erinnerungen eines ehemaligen Pazifisten“, aus dem man gleich

35 Ebd., S. 358.

36 Ebd., S. 360.

37 Ebd., S. 363.

38 Vgl. Jesaja 65, 17-25. 
ersieht, dass Wittlin seine ambivalente Haltung zwischen Skepsis und Hoffnung aufgegeben hat. Er distanziert sich von seinem früheren, vor allem den "Hymnen" zugrunde liegenden Pazifismus. Besonders stören ihn die Nachkriegspazifisten, die früher eine kriegsbefürwortende Haltung eingenommen hatten, infolge des verlorenen Krieges aber das Banner eines oberflächlichen, snobistischen, salonfähigen Pazifismus ergriffen. Er unterscheidet genau zwischen ihnen und denjenigen Pazifisten, die noch während des Krieges, als es gefährlich war, solche Ansichten zu verbreiten, den Krieg verurteilten. Unter ihnen nennt er mit Hochachtung Autoren wie Romain Rolland oder Henri Barbusse in Frankreich, Leonhard Frank, René Schickele, Fritz von Unruh, Kurt Hiller und Karl Kraus auf der deutsch-österreichischen Seite.

Es wurden bereits Wittlins Äußerungen anlässlich des polnisch-ukrainischen Krieges um Lemberg angeführt. Der Sprecher des Essays macht hierzu Bemerkungen in seinem eigenen, biografisch haftbaren Namen sowie im Namen des früh an Tuberkulose gestorbenen polnisch-jüdischen Theoretikers und Dichters des Expressionismus Jan Stur. ${ }^{39}$ Damals befanden sich beide in einem inneren Konflikt zwischen ihrem polnischen Patriotismus, der sie zu engagierter Stellungnahme auf polnischer Seite bewog, und ihrem Pazifismus, der dazu führte, dass sie an den Kämpfen nicht teilnahmen. Wittlin freute sich über den polnischen Sieg, litt aber unter dem Judenpogrom und verstand auch die Motivation der Ukrainer, die ebenfalls aus Heimatliebe um ihr Lemberg kämpften. So kommt er zu der Ansicht, der Hass, der auf den beiden kämpfenden Seiten vorhanden war, sei eben die Kehrseite ihrer Liebe zum Vaterland gewesen. Seine aktuelle Haltung erklärt er mit dem einfachen Gleichnis, er fühle sich trotz seines geringen materiellen Vermögens beruhigt, wenn er, auf einem Landgut wohnend, immer wieder feststelle, dass ein Nachtwächter über das Gut wache. So sei es auch mit dem europäischen Frieden. Denn Wittlin war zwar ein großer Anhänger des Franziskanismus, aber er machte sich keine Illusionen darüber, ob die absolute Armut, die Franz von Assisi im Gefolge Christi praktizierte, von anderen Menschen nachgeahmt werde. Jeder, der etwas besitze, werde es verteidigen wollen oder müssen. Das habe er inzwischen gelernt.

Unter dem Begriff ${ }_{n}$ Frieden“ stelle er sich konkret zwei aus eigenem Erleben bekannte Formen vor: den Frieden, der bis 1914 herrschte, und den seit 1918. Bezüglich des ersteren Falles sei er sich bewusst, dass er diesen Frieden vielleicht idealisiere, denn das sei ja seine Jugendzeit gewesen. Man ersieht auch aus anderen Texten Wittlins, dass er die Zeit Franz Josephs und Osterreich-Ungarn als sein "Vaterland auf Zeit ${ }^{40}$ im Nachhinein verklärt.

39 Jan Stur, eigentl. Hersch Feingold, lebte in den Jahren 1895-1923. Vgl. Maria Klańska, Jan Stur und der polnische Expressionismus, in: Hartmut Kircher u. a. (Hg.), Avantgarden in Ost und West. Literatur, Musik und bildende Kunst um 1900, Köln 2002, S. 177 191.

40 Orłowski, S. 261. Zur Haltung Wittlins zu Osterreich-Ungarn vgl. auch ebd., S. 260-265. 
Aber hier argumentiert der Essayist bewusst, der Friede bis 1914 sei nicht mit solchen Opfern und solchem Schuldbewusstsein erkauft worden wie der von 1918. Seiner Erinnerung nach hätten alle Soldaten 1914-1918 nichts mehr als den Frieden ersehnt und diesen erträumten Frieden mit der Zeit zu einem Idealzustand verklärt. Dann aber sei die große Enttäuschung gekommen, denn nichts an der menschlichen Moral, nichts an den politischen Strebungen habe sich verändert. Hass, Hochmut und Egoismus herrschten nach wie vor. Wittlin bezeichnet den Frieden der Zwischenkriegszeit als einen niederträchtigen. ${ }^{41}$ Die durch die Leiden des Krieges erhoffte Katharsis habe nicht stattgefunden.

Zu groß waren die Losungen, derentwegen man im Krieg einander mordete: Freiheit, Gleichheit, Brüderlichkeit, Gott, Vaterland, Kultur, Zivilisation, Gerechtigkeit, als dass wir sie verachten sollten. Wenn der Krieg diese Parolen unberechtigt benutzte, wenn er sie defraudierte, sollte ihnen der Friede ihren Währungswert in Gold wiedergeben. Es hat sich jedoch herausgestellt, dass diese Losungen nach wie vor geheuchelt sind, dass niemand oder fast niemand an sie glaubt. $^{42}$

So distanziert sich Wittlin von den "pazifistischen Empfängen und Paneuropäern ${ }^{43}$ und rechtfertigt seinen Meinungswandel damit, nicht er habe dle Fahne seiner Jugend verraten, sondern diese Fahne ihn, seine Hoffnungen und Erwartungen.

Die Spanne von fünf Jahren zwischen den beiden Essays markiert die Evolution der Ansichten eines Autors, der tief enttäuscht und von der Entwlcklung in Europa angeekelt ist. Außerdem sieht Wittlin Ende der zwanzlger Jahre noch klarer, wie naiv und oberflächlich die pazifistischen Ideen seien. Wenn man damit noch die Vorrede zu „Orpheus in der Hölle des 20. Jahrhunderts“ vergleicht, die 1962, also bereits nach den Erfahrungen des noch viel schreckllcheren Zweiten Weltkriegs entstand, sieht man, dass der Schriftsteller jegliche Illusionen und Hoffnungen verloren hat. Während der Essayist in "Krieg, Frieden und die Dichterseele ${ }^{u}$ noch positive Seiten des Kriegsdienstes aleht und optimistisch hervorhebt: „In ihnen [den Soldaten] entsteht die Tugend der Tapferkeit, der Opferbereitschaft, der Ausdauer, der Selbstverleugnung, des Gehorsams, des Schweigens, der brüderlichen, kameradschaftlichen Liebe, vor allem aber die Fähigkeit, den Gegner zu achten", ${ }^{44}$ urteilt Wittlin 1962, dass die letztgenannte Fähigkeit, falls sie tatsächlich entstanden sein sollte, sehr kurzlebig und unter den Teilnehmern des Zweiten Weltkriegs nicht mehr zu bemerken gewesen sei. ${ }^{45}$ Man kann also insgesamt im Laufe der Jahre einen

$41 \mathrm{Vgl}$. Wittlin, Ze wspomnień byłego pacyfisty, S. 85 .

42 Ebd., S. 87.

43 Ebd., S. 91.

44 Wittlin, Krieg, Frieden und die Dichterseele, S. 330.

45 Vgl. Józef Wittlin, Przedmowa, in: Ders., Orfeusz w piekle XX wieku, S.9. 
Wandel in der Einstellung des Autors zum Krieg beobachten, von der Hoffnung, dass dem Ersten Weltkrieg ein ewiger, gerechter Friede folgen werde, bis hin zu Skepsis und Illusionslosigkeit. Dennoch bleibt Wittlin in seinem ganzen Schaffen ein überzeugter Kriegsgegner. 